\title{
Historia, ciencia y paradigmas en los orígenes de la XVIII dinastía egipcia
}

\author{
José Ramón Pérez-Accino
}

Ciencia es un nombre ambiguo. Si la Historia es o no una disciplina a la que pueda aplicarse el apelativo de científica es una polémica ya clásica en los debates introspectivos de los teóricos de la misma. La teorización y categorización sobre la disciplina en sí a menudo pueden llegar a ser inconclusivos. Se puede hacer quizá más clarificador este debate observando no tanto el qué sino el cómo. Los usos y comportamientos de los profesionales de la historia podrían ser clarificadores en cuanto a lo que el proceder de su investigación se asemeja o difiere de los usos y comportamientos de los profesionales de disciplinas científicas a las que se les confiere sin vacilar el timbre de científicas. El hecho de que el comportamiento de los historiadores en cuanto investigadores sea semejante al de los investigadores en termodinámica, por poner un ejemplo, no supone automáticamente que la disciplina lo sea de igual manera, pero sí da información positiva de cómo la disciplina en consideración, la historia, se presenta ante la sociedad que la alberga.

Son ya clásicas en la Sociología de la Ciencia las teorías que hablan del protagonismo de la comunidad de investigadores en una determinada disciplina o grupo científico en la configuración y comportamiento de las preguntas y las respuestas que esa disciplina ofrece sobre sí misma ${ }^{1}$. El grupo científico actúa como un ámbito cerrado y autoalimentado que prepara a sus componentes para responder a unas preguntas formuladas

\footnotetext{
* Profesor de Lengua Egipcia. Univ. de Londres.

1 Los términos y conceptos paradigma, ciencia normal y grupo científico se utilizan en el presente texto en el sentido expresado en KuHN, T.S. The structure of scientific revolutions. Chicago, Univ of Chicago Press (1962) como un intento de aplicar al análisis histórico las premisas de sus trabajos sobre avances, cambios y revoluciones en la ciencia. En este sentido $\mathrm{v}$. también BARNES, B. T.S. Kuhn and Social Science. Londres. MacMillan Press Ltd. (1982).
} 
desde ópticas y perspectivas creadas para eso mismo. En otras palabras, las preguntas se formulan en virtud de la información disponible para responderlas. Un panorama semejante hace difícil y penoso el avance y la formulación de nuevas preguntas que no se encuentren previamente implícitas en la información disponible para la comunidad científica en un determinado momento. Esto hace muy difícil el progreso de las disciplinas científicas y las deja a merced de circunstancias personales tales como la eliminación física de aquellos que sostienen teorías anteriores.

La actuación de un grupo científico como mantenedor de ideas y nociones aún cuando se encuentren a disposición del mismo datos que las contradicen seriamente puede ser uno de los campos en los cuales se evidencie la similitud de comportamiento de los grupos científicos en ramas del saber tan aparentemente alejadas del hecho científico como la Egiptología y aquellas en las cuales este carácter no se haya puesto en duda.

La secuencia de interpretación del episodio histórico de las primeras monarquías egipcias de la XVIII dinastía en Palestina puede ser un ejemplo para un fenómeno como el anteriormente citado. Los últimos años están viendo tambalearse algunos paradigmas en la Historia Antigua oriental que han venido gozando de buena salud a través de la bibliografía normal y especializada y afectando a la formación teórica de los investigadores y estudiosos en esa disciplina. El caso de la historia de Egipto es de relevancia e interés al suponerse paradigmático y ejemplarizador su desarrollo histórico en relación con el de otras comunidades del oriente mediterráneo. La enumeración de estos paradigmas, la razón de su eficiencia y operatividad y los planteamientos que los han hecho entrar en crisis constituyen un capítulo aparte de la historia de la Egiptología como disciplina científica. En el presente texto nos vamos a limitar a seguir las líneas maestras de la crisis de uno de estos patrones de conocimiento en el caso de la historia antigua egipcia.

Es común encontrar en manuales y bibliografía especializada la afirmación expresa o matizada de que, tras la conquista del Delta del Nilo, los monarcas de la casa tebana en la temprana dinastía XVIII se embarcan en una política declarada de intervención en el corredor sirio-palestino fundamentada en el recuerdo de la humillante experiencia que había supuesto el control de los hiksos y que conduciría inevitablemente al conflicto generalizado en tiempos de Tutmosis III y, en definitiva, serviría de prolegómeno a una política deliberada de intervención en Palestina ${ }^{2}$.

2 Esta visión puede ser observada en los autores de síntesis históricas sobre el período 


\section{Esta interpretación paradigmática puede ser ejemplificada en}

Se ha visto que luego de la expulsión de los hicsos el rey Ahmosis volvió nuevamente a Asia y realizó su primer esfuerzo en Fenicia. Esa elección estuvo determinada a la vez por el recuerdo de la influencia secular de Egipto en Fenicia y por la preocupación de conseguir para los egipcios una base marítima cómoda para sus acciones en Asia anterior. (Drioton-Vandier, op.cit. p.345)

o también especialmente en Wilson:

Por fin Egipto se vio libre del arrogante invasor... la antigua y plácida introspección y la concentración dentro del Valle del Nilo fue reemplazada por la idea de llevar las fronteras efectivas del país a territorios lejanos en Asia y Africa. Ya no bastaba exhibir ante los pueblos extranjeros la superioridad de la cultura egipcia y establecer por este medio un comercio favorable. Aquellos pueblos ya no se dejaban patrocinar por su propio bien y por el bien de Egipto; se habian mostrado rebeldes. El faraón tenía que tomarse tiempo para darles eficaces lecciones de disciplina en sus propios paises. (Wilson, op. cit. p. 243)

Esta es una afirmación que se ha hecho canónica y pregnante en relación con la interpretación histórica del período. Las campañas en Palestina de los primeros monarcas de la XVIII dinastía son tomadas como el primer episodio histórico constatable de la inclusión de esta región en el ámbito histórico del mediterráneo y de la intervención egipcia en el relato bíblico del Éxodo, una razón más para probar la veracidad de la Biblia como relato histórico.

La afirmación teórica de la implicación de los monarcas de la dinastía XVIII temprana en la conquista de territorio en Palestina buscará una comprobación empírica por la vía de la arqueología de la misma manera que se trató de dar un manto científico a la Biblia por la misma vía. La veracidad de los textos históricos egipcios sería comprobada empíricamente desde el campo de la Arqueología ${ }^{3}$. De esta manera la preeminencia en el tiempo del

desde los más clásicos como Drioton, E. y VAndier, J. (1983), Historia de Egipto. Buenos Aires. Eudeba., WILson, J.A. (1951), The burden of Egypt. An interpretation of Ancient Egyptian Culture. Chicago. Univ of Chicago press. (p.167) hasta las más recientes como GrimAL, N. (1988), Histoire de l'Egypte ancienne. París, Fayard (p.243-47) o también Trigger, B., KEMP, B., O'Connor, D. y LLord, A., Historia del Egipto antiguo. Barcelona. Crítica (1985). La lista exhaustiva de todos cuantos apoyan esta visión sería, sin duda, demasiado larga.

${ }_{3}$ Esta idea puede verse expresada en WRIGHT, G.E. «The archaeology of Palestine» en WRIGHT, G.E. (ed.) The Bible and the Ancient Near East: Essays in Honor of WIliam Foxwell Albright, Nueva York. Doubleday. DEVEr, W.G. "The beginning of the Middle Bronze Age in SyriaPalestine" en Cross, F.M., LEMKE, W.E., y MLLLER, P.D. (eds.) Magnalia Dei: The Mighty acts of God. Essays on the Bible and Archaeology fn Memory of G. Ernest Wnght. Nueva York, Doubleday. Albright, William F. TheArchaeclogy of Pafestine. A survey of the ancient peoples 
conocimiento sobre Egipto es conformador del conocimiento sobre Palestina la cual irá a remolque de la Egipcia en este punto. Mientras que el planteamiento del paradigma desde la órbita de la historiografía egiptológica es firme, ello no se corresponde completamente con el registro arqueológico en Palestina.

El paradigma está configurado a base de los elementos siguientes:

1. A la caída de Sharuhen sigue una serie de campañas egipcias de los monarcas egipcias de la dinastía XVII destinadas a establecer un escarmiento y una zona de seguridad en el corredor sirio-palestino que será el embrión del Imperio Egipcio de épocas inmediatamente posteriores.

2. Estas campañas tienen corroboración arqueológica en los niveles de destrucción constatables en la estratigrafía de las ciudades palestinas de finales del Bronce Medio.

Desde hace algunos años están a disposición de los investigadores elementos de información que contradicen esta visión paradigmática en sus elementos estructurales:

1. Los documentos históricos y arqueológicos disponibles egipcios no corroboran la visión de una actividad continuada de los monarcas de este momento en Palestina ${ }^{4}$.

2. La distribución espacial de las destrucciones de fines del Bronce Medio en Palestina no se corresponde en modo alguno con los documentos anteriores ${ }^{5}$.

3. El ejército egipcio de este momento asedia las ciudades y las reduce por hambre pero no las destruye por el fuego. No se conoce ningún ejemplo de destrucciones por el fuego debido al ejército egipcio luego las destrucciones deben tener un autor distinto ${ }^{6}$.

4. En cualquier caso, las destrucciones son demasiados numerosas para que puedan mantenerse como resultado de unas campañas que, en

and cultures of the Holy Land. Harmondsworth. Penguin, (1949), p. 87. KENYON, K.M. Arqueologia en Tierra Santa. Barcelona. Garriga (1963), p. 195.

4 La mayoría de los documentos ni tienen carácter bélico ni pueden situarse en Palestina, sino en Siria, v. REDFORD, D.B. «A Gate Inscription from Karnak and Egyptian Involvement in Western Asia during the early 18th. Dynasty". en Journal of the American Oriental Society, 99 (1979), n², pp. 270-287.

5 WEINSTEIN, J. "The Egyptian Empire in Palestine: a Reassesment" en Bulletin of the American Schools of Oriental Research, 241 (1981), pp. 1-28.

${ }^{6}$ SHEA, W. "The conquests of Sharuhen and Megiddo reconsidered en Israel Exploration Journal, 29, pp. 1-5. 
el mejor de los casos, estuvieron limitadas en el espacio y en el tiempo durante un corto período cronológico ${ }^{7}$.

Aún cuando la formulación de estas contradicciones está presente en la bibliografía, el mantenimiento del paradigma está asegurado en las obras más modernas que constituyen la ciencia normai disponible en nuestros días ${ }^{8}$.

La investigación histórica y arqueológica en ambas zonas geográficas, Egipto y Palestina, ha tenido características diferentes tanto en cuanto a método cuanto en cronología relativa de la una respecto de la otra y ello ha afectado de una manera importante a las conclusiones históricas que se han tenido en cuenta hasta el momento. En concreto, la idea de que a principios de la dinastía XVIII los monarcas egipcios se embarcaron en una actividad decidida de intervención en Palestina estaba ya firmemente establecida como paradigma en un momento en el cual la historia y la arqueología de Palestina estaban en sus más fases más incipientes de desarrollo científico. Hacia finales del siglo XIX la historia de Egipto en este período está firmemente establecida y sirve como espina dorsal o hilo conductor para el resto de las historias regionales de la zona. No es hasta bien entrado el siglo XX que Palestina comienza a ser explorada científicamente y con métodos de exploración y estudio modernos. Sin embargo, a la Arqueología de Palestina le falta Epigrafía y Arte. Palestina no puede ofrecer como Egipto o Mesopotamia largas inscripciones que proporcionen la sensación de comprender la interioridad de la experiencia histórica, como tampoco puede ofrecer restos monumentales que produzcan en aquél que los contemple la sensación de placer estético y de grandeza abandonada al olvido que es común ante la antigüedad de Egipto. El prestigio científico que aporta la Egiptología como ciencia humana emanada de la razón del siglo de las Luces y no heredada por una tradición ligada a los estudios eclesiásticos se complementa así con la vertiente moral y religiosa de una región que no tiene únicamente historia, sino que su historia es Historia Sagrada para todo aquél que tenga la Biblia como origen de su realidad religiosa.

De hecho en la configuración y desarrollo del paradigma se pueden ver varias fases que pueden ponerse en relación con momentos especialmente

\footnotetext{
7 RedFord, D.B., op. cit.

8 Particularmente en las obras que tratan del período desde la óptica de la arqueología de Palestina como AhARon,, Y. The archaeology of the land of Israel. Filadelfia. The Warminster Press. (1978), Gonen, R. «Urban Canaan in the Late Bronze Period», en Bulletin of the Amencan Schoois of Oriental Research, 253 (1984) pp. 61 y ss. y del mismo autor "The Late Bronze Age" en Ben-Tor, A. (ed.) The Archaeology of Ancient Israel. Yale Univ. Press. (1992), MAZAR, B. The Archaeology of the Land of the Bible, 10.000-586 B.C.E. Nueva York, Doubleday. (1990).
} 
importantes dentro del desarrollo de ambas disciplinas, Egiptología y arqueología de Palestina ${ }^{9}$. Para cuando se explora arqueológicamente Palestina con métodos modernos existe un esquema histórico cronológico que configura la percepción de la realidad y, por supuesto, su interpretación. El cuadro adjunto quiere expresar esta circunstancia. El esquema se mantiene aún cuando existen a disposición de los especialistas elementos de información que pondrían en seria duda la vigencia del patrón o paradigma establecido. La contradicción expresa de un paradigma por un especialista no supone generalmente la crisis del mismo, y no afecta a los elementos generales de información con los que el el propio especialista en su fase de formación tiene que aprender las herramientas básicas de su oficio.

La frase de que toda historia es historia contemporánea es cierta, y lo es aún más si cabe la de que somos todos más hijos de nuestro tiempo que de nuestros padres. El debate posmoderno ha actualizado en la medida de lo razonable la primera de las dos frases. Toda historia es historia contemporánea de textos. El destino textual del análisis histórico es tan inevitable como fructífero, tan irrenunciable como eternamente presente. Los problemas históricos son en definitiva, problemas sobre textos históricos y sólo en esta dirección toma sentido el hecho de que las ciencias afines a la historia son disciplinas humanísticas. No lo es tanto porque se refieran al hombre (la fisiología también lo es y nadie la considera particularmente humanista) cuanto que analizan la producción intelectual del hombre. Como el pasado nadie lo puede tocar, sino que es una creación mental humana, la historia es la historia de lo que el hombre piensa de su propio pasado. El pasado es un país lejano ${ }^{10}$, es un terreno mítico descrito a retazos por diferentes autores interesados en diferentes aspectos. Ese país lejano es tan ajeno a nosotros como puede serlo Eldorado, la Atlántida o el país de Nuncajamás. En la medida que es nuestro y nosotros vivimos en el hoy, ese país lejano es un problema histórico.

9 Que no arqueología bíblica.

10 Una magníhca exposición de esta idea en LowentHAL. D. The Past is a Foreign Country, Cambridge Univ Press (1993). 


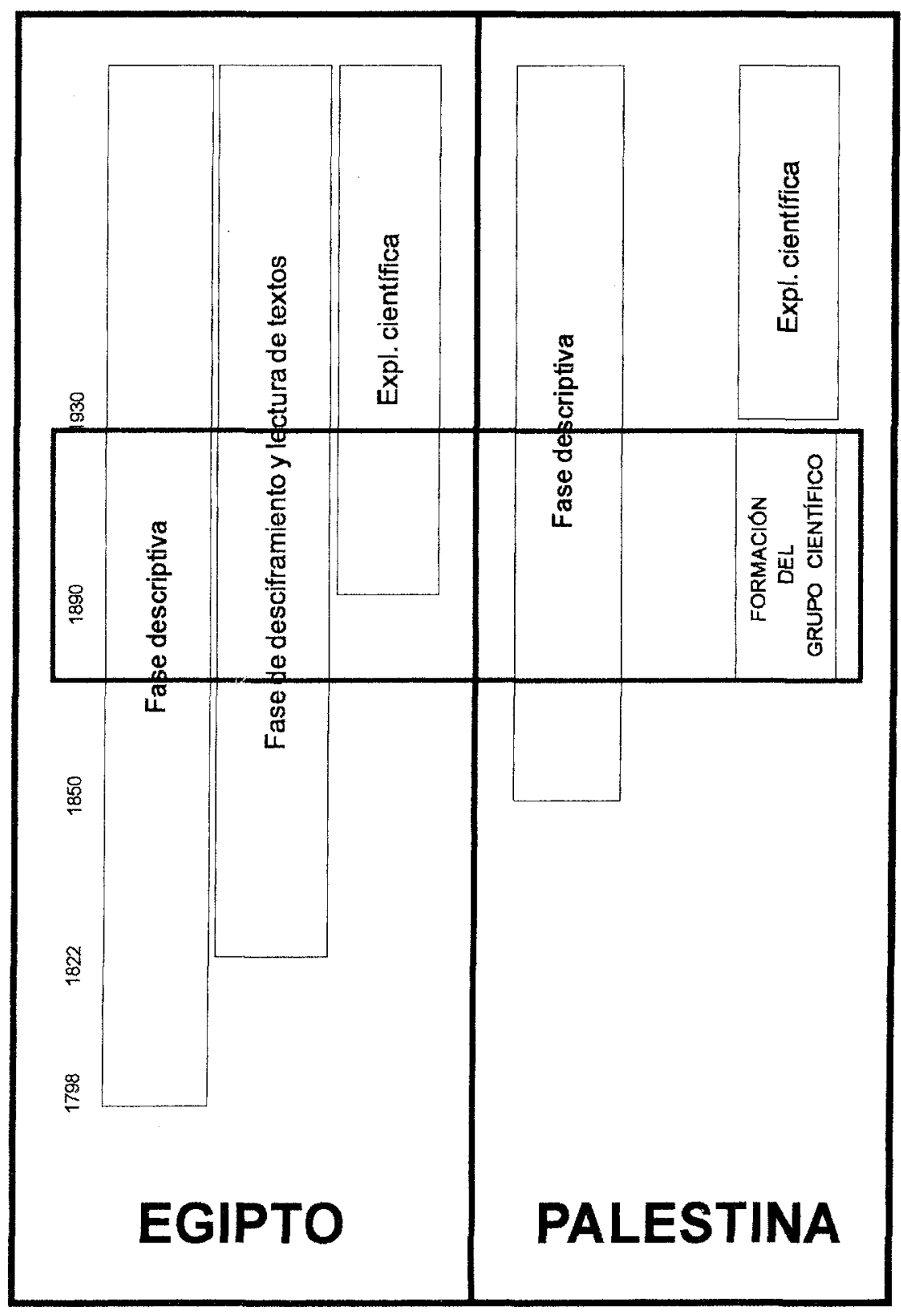

